\title{
El impacto del Covid-19 en el valor inmobiliario residencial en el Área Metropolitana de Monterrey
}

\author{
Nancy Nayeli Rosales Sotelo ${ }^{1}$ \\ ${ }^{1}$ Universidad Autónoma de Nuevo León, nallelysotelo@ hotmail.com, Pedro de Alba S/N Ciudad \\ Universitaria, San Nicolás de los Garza, N.L. 8127244694
}

Información del artículo revisado por pares

Fecha de aceptación: junio-2021

Fecha de publicación en línea: diciembre-2021

DOI: https://doi.org/10.29105/vtga7.1-97

\begin{abstract}
Resumen
El objetivo de la presente investigación es identificar el impacto del Covid-19 sobre el sector inmobiliario, considerando las condiciones de las preferencias y necesidades del individuo debido al confinamiento en vivienda residencial dentro del área metropolitana de Monterrey (AMM). Los datos se obtienen mediante una encuesta en Google Forms para hacer un análisis de las variables utilizando el programa SPSS (Statistical Package for the Social Sciences). Se trabajó en la base de datos durante marzo del 2021. Entre los principales resultados, se encontró que el $48.4 \%$ de los entrevistados de la muestra de estudio no esta dispuesto a arriesgarse a comprar una propiedad nueva, a pesar de que en su mayoría no se han visto afectados en sus ingresos. El trabajo se organiza como sigue. En la sección dos se presenta una breve revisión teórica. En la sección tres se describe el método de análisis y en la sección cuatro, la obtención de datos. En la sección cinco se reportan los resultados $\mathrm{y}$, por último, se presentan algunas conclusiones.
\end{abstract}

Palabras clave: Covid-19, Monterrey, sector inmobiliario.

\section{INTRODUCCIÓN}

La vivienda y sus características estructurales y de localización es una necesidad básica para la humanidad y desde luego, un componente

\begin{abstract}
The objective of this research is to identify the impact of COVID-19 on the real estate sector, considering the conditions of the preferences and needs of the individual due to confinement in residential housing within the metropolitan area of Monterrey (AMM). The data are obtained through a survey in Google Forms to analyze the variables using the SPSS program (Statistical Package for the Social Sciences). The database was worked on during March 2021. Among the main results, it was found that $48.4 \%$ of the interviewees in the study sample are not willing to risk buying a new property, even though most of them are not their income has been affected. The work is organized as follows. In section two a brief theoretical review is presented. Section three describes the method of analysis and section four, data collection. In section five the results are reported and, finally, some conclusions are presented.
\end{abstract}

Keywords: Covid-19, Monterrey, real estate sector.

JEL: G1, G10, G12.

importante de la inversión (Moreno y Alvarado, 2011). En muchos países la vivienda es el mayor componente de riqueza, puesto que, este sector es esencial para la 
economía, aunque también es un sector que ha sido fuente de vulnerabilidad y crisis (Zhu, 2014). Por lo tanto, a partir de la pandemia de COVID-19 el futuro se ha transformado en un desafío incierto, en el que todos los sectores manejan escenarios de indecisión.

El sector inmobiliario es una de las industrias que más ha sido impactada por la situación económica, la incertidumbre y los esquemas de distanciamiento social planteados por los gobiernos (Deloitte, 2020). Ante el gran aumento de contagios y la tasa de mortalidad en México, el gobierno mexicano ordenó la suspensión de las actividades económicas no esenciales para contener la transmisión del virus y es por lo que se está modificando la forma en la que trabajamos, vivimos, consumimos bienes y servicios, sin distinguir género, edad, nivel social o lugar de residencia.

(Engel y Volkers, 2020) aseguran dos cosas: la primera es que la vivienda sigue siendo una inversión estable en este periodo de crisis y que, por lo tanto, la pandemia no esta afectando a la compraventa de viviendas ya que en estos tiempos que corren los bienes inmuebles no han dejado de tener atractivo para los inversores. Y la segunda es que los sectores de hotelería, restauración y comercio minorista si están pasando por momentos de crisis por la pandemia actual, podría crecer la demanda de lugar de almacenamiento y almacenes.

El objetivo de la presente investigación es identificar el impacto del COVID-19 sobre el sector inmobiliario, considerando las condiciones de las preferencias y necesidades del individuo debido al confinamiento en vivienda residencial. Los datos se obtienen mediante una encuesta en Google Forms, para hacer un análisis de las variables utilizando el programa SPSS. Se trabajó en la base de datos durante marzo 2021.

En este contexto, es interés de esta investigación contestar las siguientes preguntas de investigación ¿Cómo afecto la pandemia por COVID-19 a la plusvalía de una propiedad residencial? ¿Es buen momento para adquirir una nueva propiedad? Para dar respuesta a estas preguntas haremos un análisis bajo descriptivos como análisis de frecuencia, para identificar que tan fuerte y seria es la crisis económica en el sector inmobiliario.

Para comprender más del impacto del COVID-19 en el sector inmobiliario, primero hay que ver cómo afecta a la economía en todos los países. Y en forma simplificada (Baldwin, 2020) expresa que los hogares poseen capital y trabajo, que venden a las empresas, que los utilizan para fabricar cosas que los hogares luego compran con el dinero que les dan las empresas, completando así el mecanismo y manteniendo la economía en marcha.

Es por ello por lo que la economía sigue funcionando solo cuando el dinero sigue fluyendo por el mismo mecanismo. Y una sola interrupción del flujo en cualquier momento provoca una desaceleración en todas partes. Un ejemplo claro de las interrupciones que pudiera llegar a presentarse es el desempleo, presentando dificultades financieras en el hogar.

La hipótesis que se intenta probar dentro del presente estudio es que la crisis ha roto el ritmo del crecimiento de capital y trabajo en las viviendas, esto desincentiva la inversión privada de viviendas.

\section{MARCO TEÓRICO}

A continuación, podemos encontrar el fundamento teórico de diversos argumentos acerca del presente estudio.

Es importante mencionar que las fuertes medidas involuntarias implementadas para combatir el brote de COVID-19, más las reducciones voluntarias en la actividad económica, han afectado gravemente la actividad económica. Los niveles elevados de incertidumbre combinados con datos que cambian rápidamente han disminuido la confiabilidad de los pronósticos a corto plazo (Jones Lang LaSalle, 2020).

El sector inmobiliario fue afectado con el distanciamiento social planteado por el gobierno, ya que se paralizaron las construcciones y esto ocasionó penalizaciones que se tuvieron que pagar por demora de las entregas (Narvaez, 2021).

La vivienda es uno de los espacios en el 
que más tiempo pasamos y debe ser un lugar de inspiración y descanso que nos acoja con el mayor bienestar posible. De ahí la importancia de la arquitectura residencial que suele basarse en una elección de materiales de excelente calidad, buscando componentes de larga durabilidad y sobre todo resistencia al uso, a diferencia de otros tipos de arquitectura que no requieren tal dureza (estudio 3 arquitectos, 2020).

Martínez (2005) menciona que el mercado de la vivienda se dice que es el conjunto de transacciones, acuerdos e intercambios entre compradores y vendedores y consta de tres agentes: productor, consumidor y estado. El equilibrio de mercado es la situación que se produce cuando en el mercado la oferta es igual a la demanda, es decir, vacía el mercado y los agentes quedan satisfechos.

1. Precio superior al de equilibrio $=$ Exceso de oferta.

2. Precio inferior al de equilibrio $=$ Exceso de demanda.

Una vez expuestos los significados de vivienda y mercado, es importante mencionar la vivienda como objeto de mercado, conocer los medios de provisión residencial convencionales que engloban en sí mismo el modelo residencial. A continuación, (Díaz y Zubillaga, 2021) mencionan cuatro vías de acceso basadas en la vivienda como objeto de mercado:

1. Compra: Acceso a vivienda mediante el mercado de inmuebles, nos hacemos propietarios pagando el precio de venta a la persona que en ese momento sería propietaria de la vivienda a adquirir. Una vez pagado, somos propietarios $\mathrm{y}$ podemos revender el inmueble.

2. Alquiler: Acceso a vivienda mediante el abono monetario en concepto de uso y disfrute del inmueble a el/la propietario/a de la vivienda. Esto nos permite vivir en el inmueble, una vez se rescinde el contrato, la persona propietaria es quien decide sobre la vivienda.

3. Cesión: Acceso a vivienda por decisión de las personas propietarias, que serán quienes cedan el derecho de uso. Puede producirse de progenitores a la prole o de empresas a personas empleadas, sin descartar la herencia como forma ultima de cesión, donde no solo es cedido el uso y disfrute sino también la propiedad.

4. Autoconstrucción: La vivienda es construida por la propia persona o empresa usuaria, aquí partimos de la propiedad del suelo y si calificación urbana.

Uno de los aspectos importantes a tratar en esta investigación son las preferencias del consumidor que determinan el consumo de la vivienda residencial y entre ellas encontramos las características de la vivienda, el precio, los precios relativos de las demás viviendas, la renta del consumidor, la calidad de la vivienda y los gustos del consumidor.

Existe cierta controversia respecto de si la crisis provocada por la pandemia actual está provocando realmente una crisis también en el sector inmobiliario. Algunos autores debaten respecto si Covid-19 está provocando en realidad una crisis o solamente ataca de forma tangencial, por ejemplo, Melguizo (2020) indica que, aunque no tan fuerte como la anterior, estamos ante una nueva crisis del sector inmobiliario. Housfy (2020) afirma que el sector de la compraventa de inmuebles quedará tocado, pero no hundido, ya que se realizaron planeaciones en 2020 que en la anterior crisis financiera de 2008 no se llevaron a cabo. Inmobiliare (2020) indica que, el panorama del mercado de vivienda de los segmentos residencial y residencial plus han mostrado crecimiento positivo en los últimos diez años.

En cuanto a la reactivación económica se investigó que ante la crisis económica desatada por la pandemia del COVID-19, la cual ha provocado el desempleo de más de un millón de personas, el gobierno de México diseñó un plan de reactivación económica escalonada basado en tres etapas: primero se reactivaron los municipios con pocos o nulos contagios; posteriormente se reactivaron algunos sectores clave considerados como esenciales, y la tercera etapa de reactivación 
está regida por una sistema de semáforo que va definido gradualmente qué sectores se deben reabrir y cuáles no (Ramírez, 2020).

Por otro lado, BBVA (2021), menciona cuatro mensajes clave para entender la situación inmobiliaria en México:

1. La construcción tocó fondo y modera su caída. La edificación productiva podría ser la primera en recuperarse gracias a la industria y el comercio exterior.

2. Menor costo de crédito ayudó a amortiguar la caída de la demanda por crédito para adquisición de vivienda en todos los estados del país.

3. El mercado hipotecario se contrae ante menor demanda, sobre todo del segmento de interés social y medio. Aun así, la apreciación de la vivienda continua.

4. En la última década la banca comercial ha otorgado más de un millón de créditos para adquirir vivienda. Aun así, la necesidad de vivienda sigue creciendo.

\section{MÉTODO}

Se trabajó en la base de datos durante marzo del 2021, tiempo fundamental donde se puede observar un impacto real a casi un año de su inicio en México. Para poder dar a las preguntas de investigación se utilizan los datos obtenidos de la encuesta. Se aplicó a personas de nivel socioeconómico medio-alto y alto, ya que nuestro estudio está enfocado a nivel residencial y que por supuesto viven dentro del AMM. Para captar la información de la encuesta mencionada anteriormente se utilizó la técnica encuesta de modo digital para evitar el contacto con personas, mayor practicidad y rapidez que estuvo constituido por 20 preguntas que fueron creadas en la plataforma Google Forms, y que se recabó un total de 102 encuestas. Todas se llevaron a cabo por medio de redes sociales (WhatsApp y Facebook). Es de interés mencionar que se utilizó el tipo de muestreo no probabilístico por conveniencia.

La primera parte de la encuesta tiene una serie de preguntas de control como son edad, género, estado civil, etcétera; la segunda sección está enfocada en los factores laborales de los ciudadanos encuestados, el objetivo de la tercera sección fue indagar si los sujetos de estudio prefieren su residencia en sectores privados y qué factores toman en cuenta al momento de adquirir una. Finalmente, la última sección se refiere al costo de sus residencias teniendo en cuenta que hay municipios dentro del AMM de gran demanda, la plusvalía, el declive, el aumento o la conservación del valor de la residencia.

\section{RESULTADOS}

Asimismo, para dicha determinación se aplica los efectos de las variables explicativas afectadas por el COVID-19 sobre el valor residencial. En el siguiente Cuadro 1 se presenta la información general de las 102 personas entrevistadas con residencia dentro del AMM. El análisis descriptivo de las variables se aprecia que las cifras de 2021 destacan que de las personas entrevistadas la mayoría son mujeres y el 50\% entre hombres y mujeres están casados. Fueron entrevistadas 41 personas que tienen entre 35 a 45 años, representando un $40 \%$ de las personas entrevistadas, mientras que 39 personas están entre la edad de 24 a 34 años donde se concentra el $38 \%$ de los ciudadanos entrevistados. También se muestra que en los municipios donde más respuestas se obtuvieron es en Monterrey ocupando un 29\% y San Pedro Garza García con un 24\%. La situación laboral actual de los ciudadanos entrevistados dice que $64 \%$ trabajan de tiempo completo, mientras que $29 \%$ trabaja por cuenta propia.

Cuadro 1. Características de sujeto de estudio

Género $\quad$ Frecuencia $\quad$ Porcentaje




\begin{tabular}{|c|c|c|c|}
\hline Válidos & Hombre & 41 & 40.2 \\
\hline & Mujer & 61 & 59.8 \\
\hline & Total & 102 & 100.0 \\
\hline \multicolumn{4}{|c|}{ Estado civil } \\
\hline \multirow{5}{*}{ Válidos } & Soltero(a) & 36 & 35.3 \\
\hline & Casado(a) & 51 & 50 \\
\hline & Divorciado(a) & 9 & 8.8 \\
\hline & Viudo(a) & 6 & 5.9 \\
\hline & Total & 102 & 100.0 \\
\hline \multicolumn{4}{|c|}{ Edad } \\
\hline \multirow[t]{6}{*}{ Válidos } & De 24 a 34 años & 39 & 38.0 \\
\hline & De 35 a 45 años & 41 & 40.0 \\
\hline & De 46 a 56 años & 13 & 12.7 \\
\hline & De 57 a 67 años & 9 & 8.8 \\
\hline & Total & 102 & 100 \\
\hline & Municipio de residencia & & \\
\hline \multirow[t]{12}{*}{ Válidos } & Monterrey & 30 & 29.4 \\
\hline & Guadalupe & 8 & 7.8 \\
\hline & Apodaca & 8 & 7.8 \\
\hline & San Nicolas de los Garza & 10 & 9.8 \\
\hline & General Escobedo & 11 & 10.8 \\
\hline & San Pedro Garza García & 25 & 24.5 \\
\hline & Santa Catarina & 4 & 3.9 \\
\hline & Juárez & 1 & 1.0 \\
\hline & García & 3 & 2.9 \\
\hline & Santiago & 2 & 2.0 \\
\hline & Total & 102 & 100.0 \\
\hline & Ingreso salarial mensual & & \\
\hline \multirow[t]{7}{*}{ Válidos } & Menos de $\$ 40,000$ & 35 & 34.3 \\
\hline & $\$ 40,001-\$ 60,000$ & 17 & 16.7 \\
\hline & $\$ 60,001-\$ 80,000$ & 29 & 28.4 \\
\hline & $\$ 80,001-\$ 100,000$ & 17 & 16.7 \\
\hline & Más de $\$ 100,001$ & 4 & 3.9 \\
\hline & Total & 102 & 100.00 \\
\hline & Situación laboral actual & & \\
\hline \multirow[t]{5}{*}{ Válidos } & Empleo de medio tiempo & 5 & 4.9 \\
\hline & Empleo de tiempo completo & 65 & 63.7 \\
\hline & Trabajador por cuenta propia & 30 & 29.4 \\
\hline & Jubilado & 2 & 2.0 \\
\hline & Total & 102 & 100.0 \\
\hline
\end{tabular}

Fuente: Elaboración propia.

De acuerdo con el Cuadro 2, el $41 \%$ de las personas entrevistadas trabajan desde casa y, la pandemia no afecto los ingresos de $59.4 \%$ de los encuestados, esto quiere decir que afortunadamente más de la mitad siguen contando con su ingreso salarial completo.
Solamente el $11 \%$ de los entrevistados creen que la plusvalía de su residencia bajó, mientras que el $88 \%$ aseguran que la plusvalía de sus residencias se mantuvo. 
Cuadro 2. Variables de las personas de estudio

\begin{tabular}{llcc}
\hline \multicolumn{1}{c}{ Variable } & & Frecuencia & Porcentaje \\
\hline Trabajo desde casa & Sí & 42 & 41.2 \\
& No & 60 & 58.8 \\
& Total & 102 & 100.0 \\
\hline Afectación a su ingreso salarial & Sí & 41 & 40.2 \\
& No & 60 & 59.4 \\
& Perdidos & 1 & 1.0 \\
& Total & 102 & 100.0 \\
\hline La plusvalía de su residencia bajó & Sí & 11 & 10.8 \\
& No & 90 & 88.2 \\
& Perdidos & 1 & 1.0 \\
& Total & 102 & 100.0 \\
\hline
\end{tabular}

Fuente: Elaboración propia.

En cuanto a las características de la vivienda residencial, considerando la información y los datos recabados del cuadro 2 y 3 , obtuvimos que el motivo más demandado por estar trabajando en casa es por medidas de contingencia reflejando un $55.81 \%$ mientras que el $30 \%$ es porque siempre ha trabajado desde su casa. Con respecto al segmento habitacional donde les gustaría vivir, se observa que el $81.37 \%$ prefiere vivir en un fraccionamiento privado y que un $10.78 \%$ prefieren su residencia en una colonia municipal y por último solamente el $7.84 \%$ considera vivir en un departamento.

Cuadro 3. Variables de las personas de estudio

\begin{tabular}{llcc}
\hline \multicolumn{1}{c}{ Variable } & & Frecuencia & Porcentaje válido \\
\hline Trabajo desde casa & Su trabajo lo ordenó & 6 & 13.95 \\
debido a: & Siempre ha trabajado desde casa & 13 & 30.23 \\
& Por medidas de contingencia & 24 & 55.81 \\
\hline Afectación de ingreso & Desempleo & 5 & 11.36 \\
salarial debido a: & La empresa redujo su sueldo & 14 & 31.82 \\
& Incrementaron sus gastos & 25 & 56.82 \\
\hline Segmento habitacional & Fraccionamiento privado & 83 & 81.37 \\
preferible para vivir & Colonia municipal & 11 & 10.78 \\
& Departamento & 8 & 7.84 \\
\hline
\end{tabular}

Fuente: Elaboración propia.

En Gráfica 1 se presentan los resultados de algunos factores más importantes que las personas consideran al momento de adquirir una vivienda de tipo residencial, teniendo como resultado que un $28.43 \%$ de las personas encuestadas prefieren contar con seguridad, el $20.59 \%$ prefieren tener acceso a vías principales, un $13.73 \%$ consideran que tenga terreno excedente, $10.78 \%$ que se ubiquen frente a parque, un $6.86 \%$ prefieren 
ubicación en esquina y $7.84 \%$ eligen hospital. considerar poco tráfico y vivir cerca de un

Gráfica 1. Factores por considerar al comprar una residencia en el AMM, 2021.

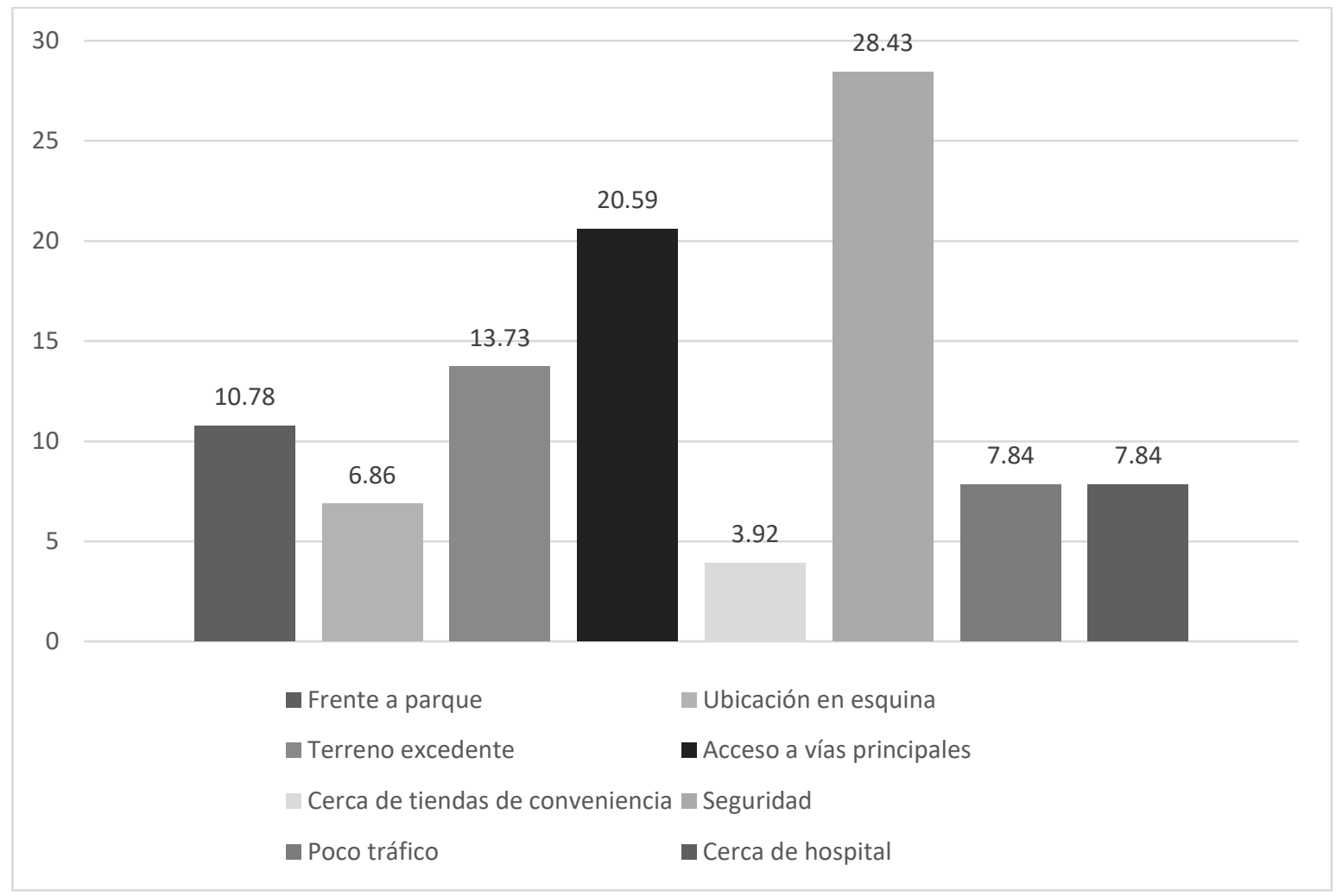

Fuente: Elaboración propia.

En la Gráfica 2 se observan los factores que afectan de manera directa en el declive del valor de la residencia, obteniendo como resultado que por la situación de la pandemia el $39.13 \%$ cree que afecta porque la colonia no es privada, lo que beneficia el tránsito de personas ajenas a la colonia y por lo tanto aumenta el riesgo de contagio, un $34.78 \%$ refleja que las personas que se consideran de clase social media-alta, se vio afectada por el desempleo, asimismo, un $13 \%$ considera que en la zona aumentaron el número de contagios y que la residencia está ubicada lejos de un lugar de atención médica.

Gráfica 2. Factores que afectan de manera directa en el declive del valor en el AMM, 2021. 


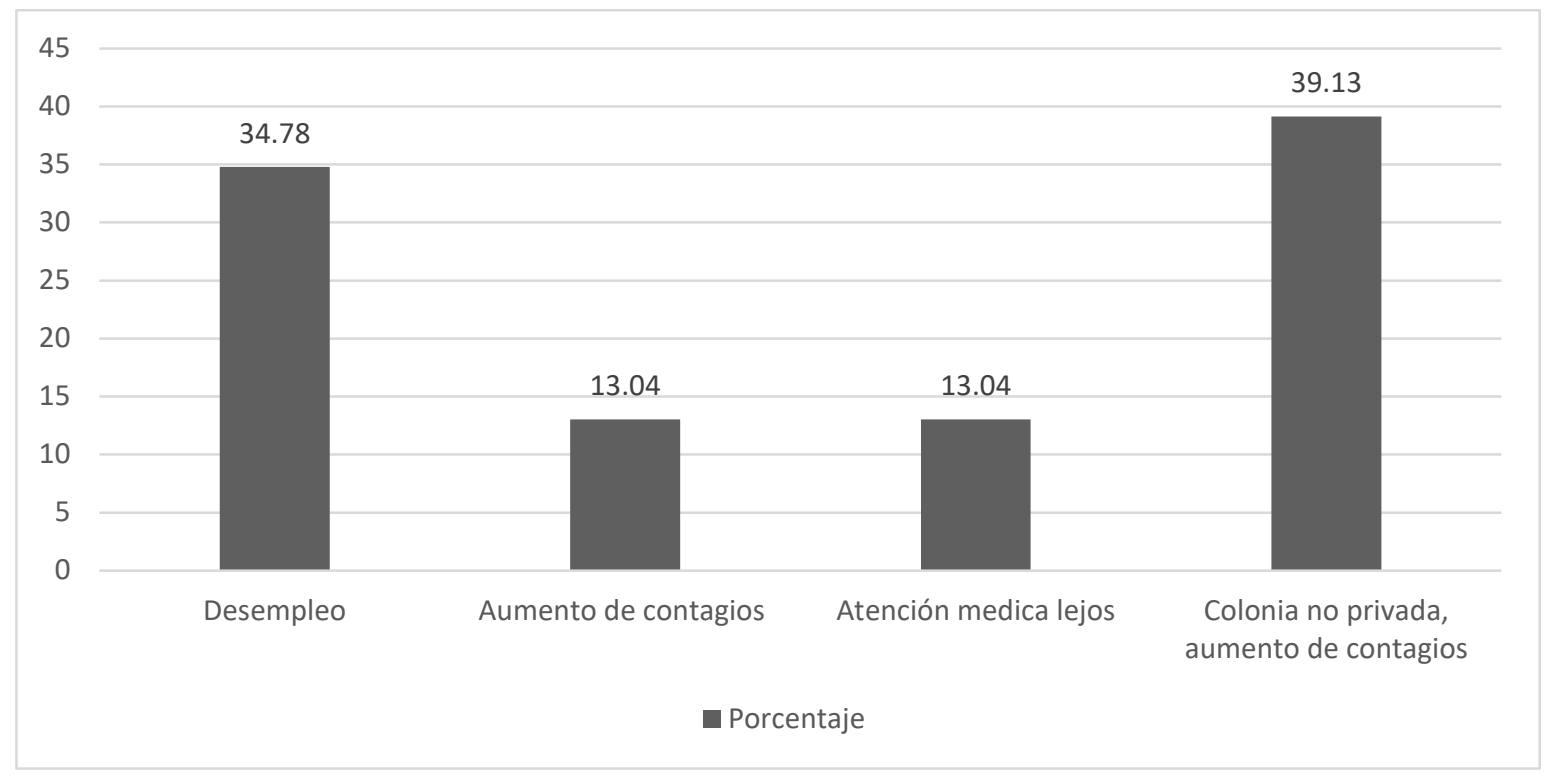

Fuente: Elaboración propia.

En la Gráfica 3; se reflejan los resultados que se obtuvieron de los factores que se consideran para que la residencia conservara el mismo valor a pesar de la situación actual, un $28 \%$ opina que es por la cantidad de $\mathrm{m} 2 \mathrm{de}$ construcción, el $32.79 \%$ dice que es por la cercanía de la ubicación del predio respecto al centro del área metropolitana, el 18\% considera el factor de calidad en los acabados y procesos constructivos. También se detectó que el $21.31 \%$ es por la calidad de bienes ambientales cercanos como parques, plazas, jardines, etcétera.

Gráfica 3. Factores que influyen a conservar el mismo valor de una residencia en el AMM, 2021.

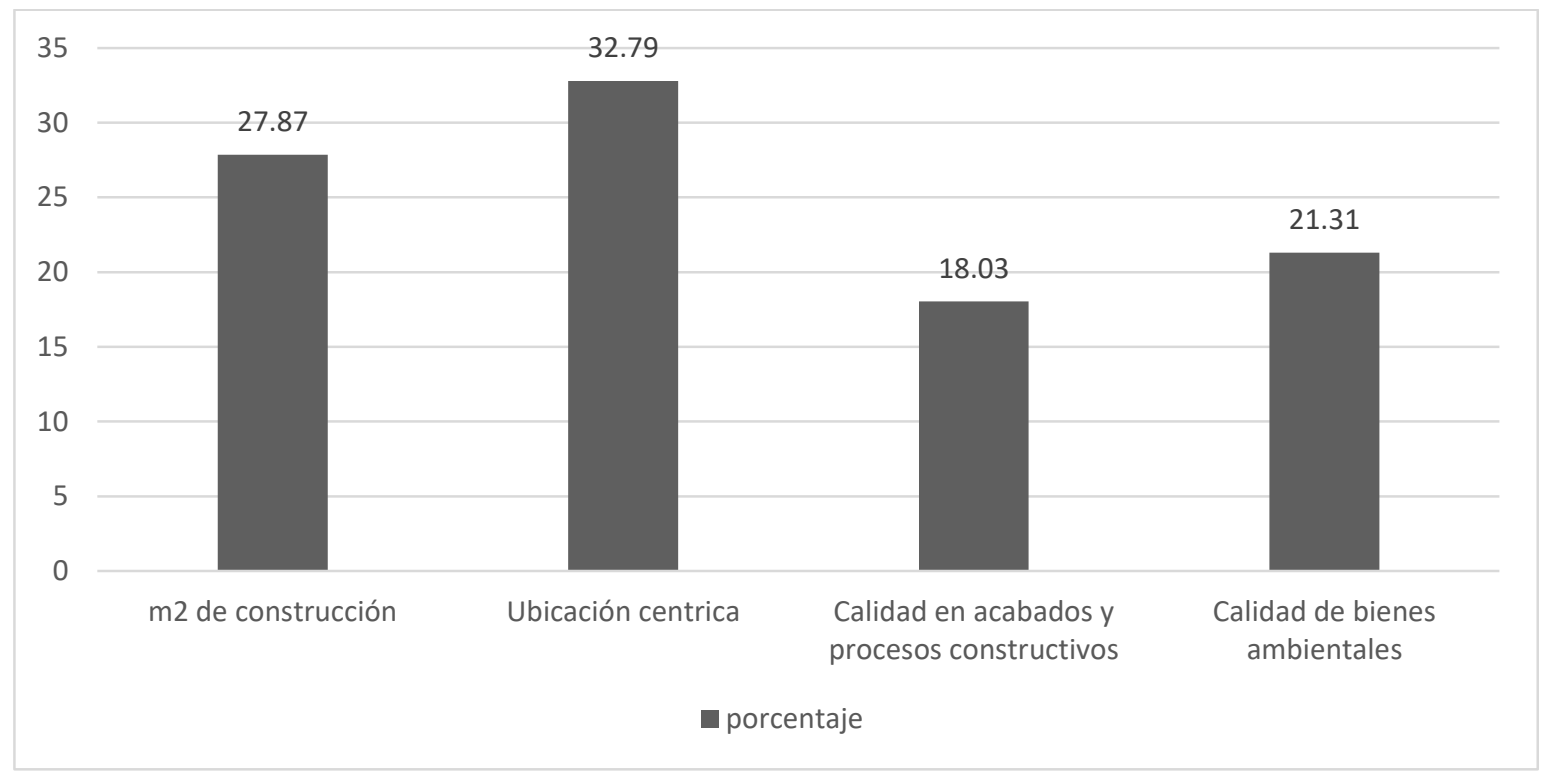

Fuente: Elaboración propia.

Asimismo, la Gráfica 4 presenta los factores que consideran los encuestados para que una residencia aumente su valor aún con la situación de la pandemia actual. El $44.62 \%$ de 
las personas entrevistadas consideran que el aumento en la demanda de viviendas se debe a las condiciones del según el mercado (a mayor demanda es mayor la oferta), el $15.38 \%$ opina que es la necesidad por parte del gobierno reactivar la economía, lo que hizo que se proporcionaran diferentes apoyos o modificaciones a los existentes, como el
Infonavit, el $32.31 \%$ dice que por la iniciativa de los bancos por tener tasas y planes más atractivos para la adquisición de viviendas y un $7.69 \%$ considera como factor a mayor número de decesos debido al contagio, hay más propiedades disponibles, por lo cual es más atractiva la oferta de venta de estas viviendas.

Gráfica 4. Factores por considerar a que aumente el valor de una residencia en el AMM, 2021

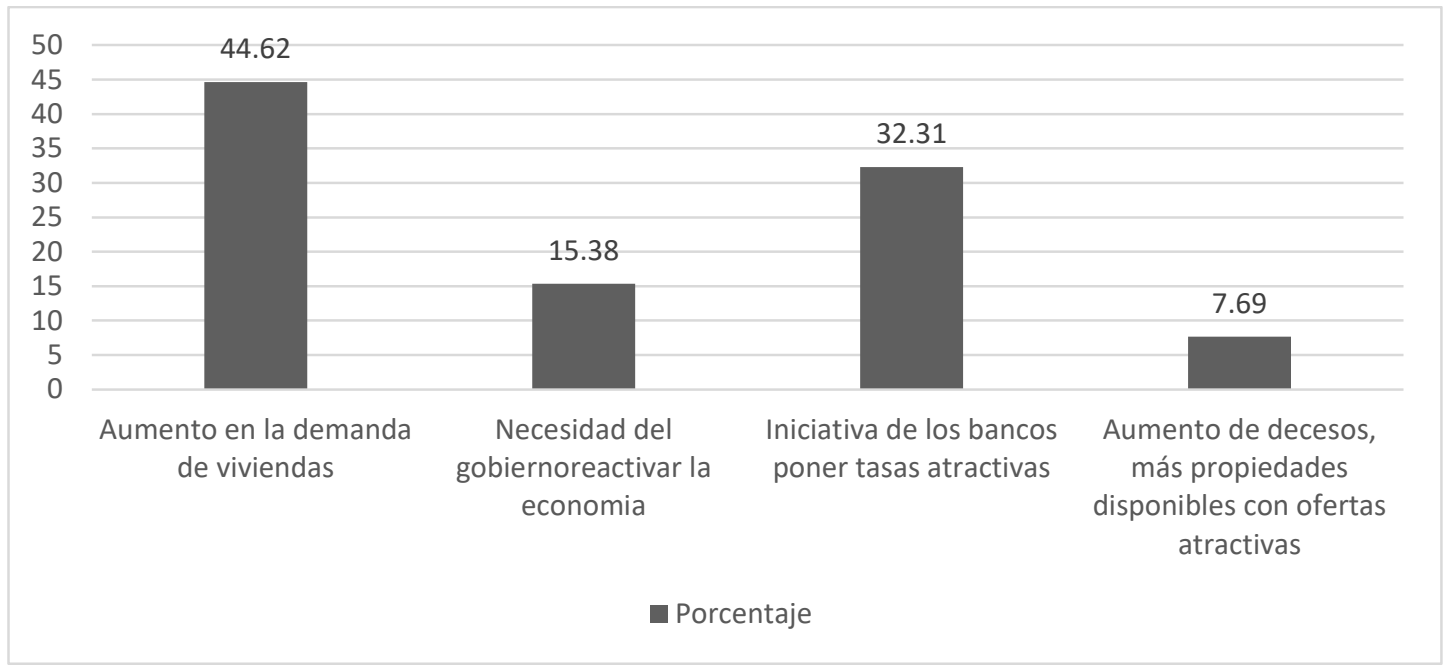

Fuente: Elaboración propia

Por último, la Gráfica 5 presenta uno de los datos más importantes, en donde se observa que a pesar del COVID-19 el $29.41 \%$ dice que solicitaría un crédito bancario, el $3.92 \%$ acepta y que la pagaría de contado, un $18.63 \%$ compraría una residencia si vende su propiedad actual y, finalmente el $48.04 \%$ no comprarían una residencia para no correr riesgos.

Gráfica 5. Factores que inciden sobre la decisión de adquirir nueva residencia en el AMM 2021.

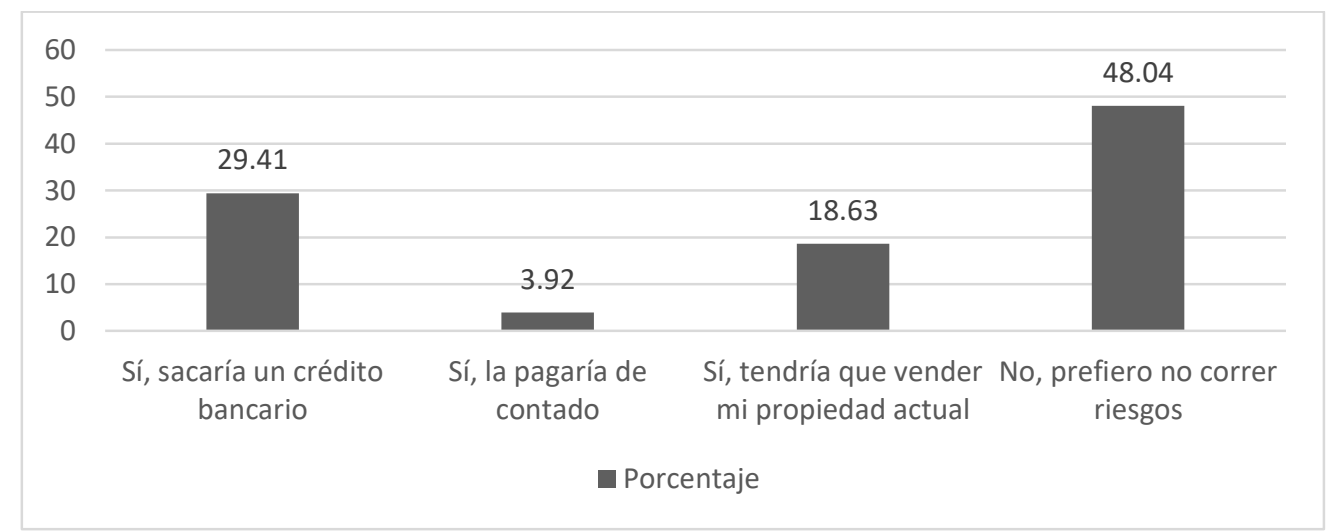

Fuente: Elaboración propia. 


\section{CONCLUSIONES}

El impacto del COVID-19 provocó una crisis mundial con graves consecuencias, sobre todo en la economía. Si bien el impacto que tuvo en el valor residencial no fue muy castigado, porque por el momento, los precios de las residencias en el sector comercial son estables. Los datos de la investigación arrojaron que a pesar de que no ha habido un descenso significativo en el valor de las propiedades de este nivel social (residencial), si ha bajado la demanda de estas, cerca de la mitad de los entrevistados de la muestra de estudio no está dispuesto a arriesgarse a comprar una propiedad nueva, a pesar de que en su mayoría no se han visto afectados en sus ingresos, pero el $56 \%$ confirmó que aumentaron sus gastos, la incertidumbre del efecto post-pandemia no los deja tomar un compromiso tan grande en cuanto a, financiamiento bancario se refiere (aún con tasas especiales) o de gastar sus ahorros en el caso de comprarla de contado.

Considerando los resultados obtenidos de las preferencias y necesidades del individuo, se verificó que quienes si están de acuerdo en conseguir una vivienda prefieren comprar dentro de un fraccionamiento privado que pueda contar con seguridad y ubicarse cerca de avenidas principales.
Con los resultados obtenidos se menciona que el $10 \%$ de los entrevistados opina que la pandemia por COVID-19 afectó a la plusvalía de una propiedad residencial y esto se puede ver reflejado en que la colonia en donde habitan no es privada, lo que beneficia el tránsito de personas ajenas a la colonia y por lo tanto aumenta el riesgo de contagio, así como la ubicación de servicios e infraestructura lejos.

A pesar de los esfuerzos que han hecho las entidades financieras con las tasas de interés especial que pudieran ser atractivas para la población, las personas no creen que sea un buen momento para adquirir una vivienda, ni con crédito hipotecario, ni de contado, y los que si están dispuestos en su mayoría tendrían que vender la propiedad actual para poder capitalizarse.

Entonces, aunque porque el momento (corto plazo) no se ha visto realmente afectado el valor de esta propiedad, en algún lapso del mediano o largo plazos se tendrán que modificar los costos como estrategia para reactivar la demanda del sector inmobiliario, ya que la oferta no puede seguirse manteniendo mientras la demanda vaya en descenso, este es un aspecto fundamental que en todo sector económico y de mercado influye para los valores del mismo. 


\section{REFERENCIAS}

Baldwin, R. (2020). Keeping the light on: Economic medicine for a medical shock. VoxEU. En: https://voxeu.org/article/how-should-we-think-about-containing-covid-19-economiccrisis

Deloitte, T. (DELOITTE). (2020). Impacto del Covid-19 en el mercado inmobiliario. En: https://www2.deloitte.com/content/dam/Deloitte/cr/Documents/tax/documentos/impactodel-covid19-en-el-mercado-inmobiliario

Díaz, C. \& Zubillaga, C. (2020). La percepción de las familias residentes en el municipio de Candelaria sobre el impacto y efecto de la COVID-19 y el riesgo para la exclusión residencial. Candelaria: Universidad de la Laguna. En: https://riull.ull.es/xmlui/bitstream/handle/915/20759/La\%20percepcion\%20de\%20las\%20fa milias\%20residentes $\% 20 \mathrm{en} \% 20 \mathrm{el} \% 20$ municipio\%20de\%20Candelaria\%20sobre\%20el $\% 20$ impacto $\% 20 \mathrm{y} \% 20 \mathrm{efecto} \% 20 \mathrm{de} \% 20 \mathrm{la} \% 20 \mathrm{COVID}-$ $19 \% 20 \mathrm{y} \% 20 \mathrm{el} \% 20 \mathrm{riesgo} \% 20$ para\%201a\%20exclusion\%20residencial,.pdf?sequence $=1$

Engel \& Völkers (2020). Crisis inmobiliaria debido al coronavirus ¿Recesión en el mercado? En: https://www.engelvoelkers.com/es-es/crisis-inmobiliaria-coronavirus/

Estudio 3 arquitectos (2020). ¿Qué caracteriza a la arquitectura residencial? En: https://www.estudio3arquitectos.com/arquitectura-residencial/

Flores, C. (2020). Efectos de la crisis del COVID-19 sobre el mercado inmobiliario local. Cartagena: Universidad Politécnica Cartagena. En: https://repositorio.upct.es/bitstream/handle/10317/9111/tfg-floefe.pdf?sequence $=1 \&$ isAllowed $=y$

Housfy (2020). ¿Cómo afectará al mercado inmobiliario? En: https://housfy.com/blog/crisis-2020como-afectara-al-mercado-inmobiliario/

Inmobiliare (2020). Panorama de la vivienda en México. En: https://inmobiliare.com/panorama-dela-vivienda-en-mexico/

JLL Research \& Strategy (2020). Covid-19: Implicaciones mobiliarias globales. JLL. En: https://www.jll.com.mx/es/trends-and-insights/research/covid-19-global-real-estateimplications

Martínez, X. (2005). El mercado de la vivienda. Microeconomía avanzada I. En: http://code.uab.es/xmg/Docencia/MicroAv1/Curs0809/Habitatge01.pdf

Melguizo, J. (2020). La pandemia golpea al inmobiliario: el precio de la vivienda caerá hasta un 6.5\& en $2020 . \quad$ Bolsamanía. En: https://www.bolsamania.com/noticias/economia/pandemia-golpe-inmobiliario-vivienda2020--7417921.html

Moreno, R. \& Alvarado, E. (2011). El entorno social y su impacto en el precio de la vivienda: un análisis de precios hedónicos en el área metropolitana de Monterrey. Trayectorias, 14(33), pp. 131-147.

Narvaez, S. L. (2021). Estrategias financieras para el incremento de la rentabilidad de las empresas inmobiliarias distrito de Huancayo post COVID19. Huancayo: Universidad Continental. En : https://repositorio.continental.edu.pe/bitstream/20.500.12394/8690/1/IV_FCE_310_TI_Nar vez_Carhuaricra_2021.pdf

Ramirez, M. (2020). Ante la pandemia, ¿cómo podemos reactivar la economia? Transferencia TEC. En : $\quad$ https://transferencia.tec.mx/2020/06/30/como-podemos-reactivar-laeconomia/\#: :text=Ante\%201a\%20crisis\%20econ\%C3\%B3mica\%20desatada, $\% \% 20$ nulos\% 20contagios\%3B\%20posteriormente\%20se

Zhu, M. (12 de junio de 2014). La función del sector inmobiliario. Los mercados inmobiliarios, la estabilidad financiera y la economía. Fondo Monetario Internacional, Estados Unidos de América. 